\title{
Bone Mineral Content of the Lumbar Spine and Lower Extremities Years After Spinal Cord Lesion
}

\author{
F. Biering-Sørensen, MD, PhD, ${ }^{1}$ H. Bohr, MD, ${ }^{2}$ PhD, O. Schaadt, \\ MD $^{2}$ \\ ${ }^{1}$ Centre for Spinal Cord Injured, Department TH, ${ }^{2}$ Bone Research Unit, \\ Department TTA, Rigshospitalet, University of Copenhagen, Denmark.
}

\begin{abstract}
Summary
Bone mineral content (BMC) was measured by dual photon absorptiometry in the lumbar spine, femoral neck and shaft, and proximal tibia in 26 individuals with spinal cord lesions sustained 2 to 25 years previously. In average BMC of the lumbar spine was within the range of normal values. BMC of the femoral neck and shaft was in average $25^{\circ}$ o lower than the normal values, and for the proximal tibia more than $50^{\circ}$ o lower than the normal value. Participants with cervical lesions had lower BMC values in the femoral bones than those with thoracic lesions. Neither presence of spasticity nor daily use of long leg braces influenced the BMC significantly. Participants with previous lower extremity fractures had lower BMC values in the long bones compared with participants without fractures. The preservation of the BMC of the lumbar spine may be due to maintenance of load on the spine while sitting in a wheelchair.
\end{abstract}

Key words: Spinal cord injury; Tetraplegia; Paraplegia; Bone mineral content; Spasticity; Long leg braces; Lower limb fractures.

Osteoporosis is known to appear in patients after a spinal cord lesion (Chantraine et al., 1986; Minaire et al, 1974), and the incidence of long bone fractures in the lower extremities has been estimated to between four and seven per cent (Comarr et al., 1962; Nottage, 1981; Ragnarsson and Sell, 1981).

However, measurement of bone mineral content (BMC) after spinal cord injury has only been recorded in a few publications (Bergmann et al., 1977-78; Griffiths et al., 1972; Minaire et al., 1981; Phillips et al., 1984). The two early studies primarily measured BMC corresponding to the distal radius (Bergmann et al., 1977-78; Griffiths et al., 1972), while the two more recent studies included BMC measurements of the lower extremities in the course of a therapeutic trial (Minaire et al., 1981, Phillips et al., 1984). 
The aim of the present study was to determine BMC in the lumbar spine and the lower extremities in individuals with spinal cord lesions sustained some years previously, and to investigate the relationship of BMC to the level of the spinal cord lesion, spasticity, usage of long leg braces, and experience of lower extremity fractures.

\section{Participants}

Twenty-six individuals with spinal cord lesions were investigated 2 to 25 years after the onset of their lesion.

Table I shows that 24 were men (aged 23-65 years) and 2 women (aged 20 and 46 years). Three of the participants (nos 10,17,23) were injured in childhood (aged 5 to 10 years). Six participants were studied less than 6 years post injury, and the other 20 participants 6 to 25 years after sustaining their spinal cord lesion.

Six of the participants (no. 1 to 6 ) had complete cervical injuries regarding motor function.

Spasticity was evaluated by the history and by demonstration of increased tonus/reflexes/clonus in the lower extremities.

Mobilisation in long leg braces indicate use of the braces for standing and walking mainly with forearm crutches, at least 1 hour daily on average.

Lower extremity fractures included fractures of the femur, tibia and fibula, but not foot or toe fractures. Patients with fractures occurring before or at the time of the spinal cord injury were excluded from the study.

Seven participants (nos 9, 10,16, 17, 23, 24, 26) had a spondylodesis with Harrington rod instrumentation, and one (no. 22) with Luque rods. In all instances but one (no. 9) the rods were within the scanned area of the lumbar spine.

\section{Method}

Measurements of BMC were made by dual photon absorptiometry using the radiation energy peaks of 44 and $100 \mathrm{KeV}$ from ${ }^{153} \mathrm{Gd}$ as described by Schaadt and Bohr (1982).

The BMC of the lumbar spine was determined as the total of BMC in the second, third and fourth vertebrae (dimension mass, $U$ = arbitrary unit). In the femoral neck an average of five single scan integrals around the lowest value was chosen to represent BMC (dimension $\mathrm{U} / \mathrm{cm}$ ). For the femoral shaft the results were given as the average of five single scan integrals made transversely to the bone axis at the middle of the bone (dimension $\mathrm{U} / \mathrm{cm}$ ). For the proximal tibia the results were given as the average of five consecutive scan integrals made transversely to the bone axis in the area just distal to the subchondral plates of the tibial condyles (dimension $\mathrm{U} / \mathrm{cm}$ ) (Bohr and Schaadt, 1987).

The BMC measurements were highly correlated to bone mineral equivalents and to bone specimens. The long term precision error in standards was within $1 \%$, and the in vivo precision error was within $2 \%$ (Bohr and Schaadt 1985; Schaadt and Bohr 1982).

For technical reasons no BMC measurements were carried out on the lumbar 
Table I Basic data for participants with bone mineral content (BMC) determinations

\begin{tabular}{|c|c|c|c|c|c|c|c|c|c|}
\hline \multirow{2}{*}{$\begin{array}{c}\text { Participant } \\
\text { No. }\end{array}$} & \multirow{2}{*}{$\begin{array}{c}\text { Gender } \\
(\mathrm{M} / \mathrm{F})\end{array}$} & \multirow{2}{*}{$\begin{array}{l}\text { Age at } \\
\text { lesion } \\
\text { (years) }\end{array}$} & \multirow{2}{*}{$\begin{array}{l}\text { Years } \\
\text { since } \\
\text { lesion }\end{array}$} & \multirow[b]{2}{*}{ Cause of lesion } & \multicolumn{2}{|c|}{ Neurological motor level } & \multirow{2}{*}{$\begin{array}{c}\text { Spasticity } \\
+/-\end{array}$} & \multirow[b]{2}{*}{ Mobilisation } & \multirow{2}{*}{$\begin{array}{c}\text { Lower extremity } \\
\text { fractures since } \\
\text { lesion }\end{array}$} \\
\hline & & & & & Incomplete & Complete & & & \\
\hline 1 & $M$ & 19 & 14 & Traffic accident & C5 & $\mathrm{C} 7$ & + & wheelchair & 0 \\
\hline 2 & $M$ & 21 & 14 & Traffic accident & $\mathrm{C} 5$ & $\mathrm{C} 7$ & + & wheelchair & 1 \\
\hline 3 & $M$ & 22 & 15 & Traffic accident & & C6 & + & el-wheelchair & 0 \\
\hline 4 & $M$ & 15 & 20 & Diving accident & & C6 & + & wheelchair & 0 \\
\hline 5 & M & 28 & 10 & Diving accident & C6 & $\mathrm{C} 8$ & + & el-wheelchair & 1 \\
\hline 6 & M & 19 & 14 & Traffic accident & $\mathrm{C} 7$ & $\mathrm{C} 8$ & + & wheelchair & 1 \\
\hline 7 & M & 22 & 19 & Diving accident & $\mathrm{C} 7$ & Th10 & + & wheelchair & 1 \\
\hline 8 & M & 19 & 4 & Traffic accident & & Th4 & + & wheelchair & 0 \\
\hline 9 & M & 16 & 10 & Traffic accident & & Th4 & - & wheelchair & 0 \\
\hline 10 & M & $5 \frac{1}{2}$ & 23 & Traffic accident & & Th5 & - & wheelchair & 1 \\
\hline 11 & M & 27 & 6 & Traffic accident & Th6 & Th8 & - & wheelchair & 0 \\
\hline 12 & M & 21 & 20 & Traffic accident & Th7 & Th10 & - & wheelchair & 1 \\
\hline 13 & $\mathrm{~F}$ & 28 & 18 & Traffic accident & & Th8 & + & wheelchair & 0 \\
\hline 14 & $M$ & 42 & 23 & Haemangioma & & Th9 & - & wheelchair & 0 \\
\hline 15 & $M$ & 28 & 2 & Traffic accident & & Th10 & + & wheelchair & 0 \\
\hline 16 & $M$ & 35 & 2 & Fall & & Th10 & + & long leg braces & 0 \\
\hline 17 & $M$ & 10 & 13 & Traffic accident & & Thlo & - & wheelchair & 4 \\
\hline 18 & $M$ & 24 & 19 & Traffic accident & & Th11 & - & wheelchair & 0 \\
\hline 19 & $\mathrm{M}$ & 41 & 8 & Fall & & Th12 & + & long leg braces & 0 \\
\hline 20 & $\mathrm{M}$ & 22 & 25 & Crushed & & Th12 & + & wheelchair & 0 \\
\hline 21 & $M$ & 35 & 21 & Traffic accident & & Th12 & - & long leg braces & 1 \\
\hline 22 & $M$ & 24 & 2 & Falling tree & & Th12 & - & long leg braces & 0 \\
\hline 23 & $M$ & 7 & 17 & Shell splinter & & Th12 & - & wheelchair & 4 \\
\hline 24 & $M$ & 40 & 4 & Fall & Th12 & L3 & - & wheelchair & 0 \\
\hline 25 & $M$ & 21 & 16 & Gun shot & Th12 & $\mathrm{L} 4$ & - & long leg braces & 0 \\
\hline 26 & $\mathrm{~F}$ & 18 & 2 & Traffic accident & & L1 & - & wheelchair & 0 \\
\hline
\end{tabular}


Table II Normal values of bone mineral content (BMC) in healthy men and women

\begin{tabular}{|c|c|c|c|c|}
\hline $\mathrm{BMC}$ & $\begin{array}{c}\text { Lumbar spine } \\
\text { in } \mathrm{U}\end{array}$ & $\begin{array}{l}\text { Femoral neck } \\
\text { in } \mathrm{U} / \mathrm{cm}\end{array}$ & $\begin{array}{l}\text { Femoral shaft } \\
\text { in } \mathrm{U} / \mathrm{cm}\end{array}$ & $\begin{array}{l}\text { Proximal tibia } \\
\text { in } U / \mathrm{cm}\end{array}$ \\
\hline $\begin{array}{l}\text { Men (20-85 years) } \\
\text { (Number) } \\
\text { Mean } \pm 1 S D\end{array}$ & $\begin{array}{c}(47) \\
38 \cdot 11 \pm 5 \cdot 82\end{array}$ & $\begin{array}{c}(47) \\
2 \cdot 845 \pm 0 \cdot 389\end{array}$ & $\begin{array}{c}(42) \\
3.905 \pm 0.437\end{array}$ & $\begin{array}{c}(22) \\
6 \cdot 94 \pm 1 \cdot 12\end{array}$ \\
\hline $\begin{array}{l}\text { Women }(20-50 \text { years }) \\
\text { (Number) } \\
\text { Mean } \pm 1 S D\end{array}$ & $\begin{array}{c}(51) \\
36 \cdot 40 \pm 5 \cdot 23\end{array}$ & $\begin{array}{c}(51) \\
2 \cdot 479 \pm 0.314\end{array}$ & $\begin{array}{c}(51) \\
3 \cdot 231 \pm 0 \cdot 293\end{array}$ & $\begin{array}{c}(26) \\
5.67 \pm 0 \cdot 85\end{array}$ \\
\hline
\end{tabular}

$\mathrm{U}=$ arbitrary units in dimension mass.

spine for participant no. 2 (he was too broad to be placed between the nuclide source and the detector). Participants nos 6,10 and 17 had no measurements of the femoral necks performed because of localisation difficulties at the scanning procedure. In addition the method for BMC measurement of the proximal tibia was not introduced when participants nos $2,4,5,6$, and 17 were scanned.

BMC measurements were usually performed on both lower limbs and the results given as the average value of the right and left side. In normal populations there is no significant difference between the two sides (Bohr and Schaadt, 1982).

In the present study all BMC values are calculated in per cent of the mean values given in Table II. The data in Table II were obtained from healthy nonselected men and women in the given age-ranges.

In comparing BMC in participants with complete cervical and thoracic motor lesions, only those participants, who were at least 15 years old when the lesion occurred, and minimum 6 years post-lesion, were included. The comparison between those participants with, versus those without spasticity and long leg braces were only carried out for participants with thoracic and lumbar lesions acquired at the age of 16 years or older.

The difference in BMC between participants with and without late fracture(s) of the lower limbs was investigated only among participants who were a minimum of 10 years post-lesion. This was done to avoid a bias in the comparison regarding this parameter.

Blood samples were drawn from all the participants to check the haemoglobin concentration, ERS, serum-creatinine, -alkaline phosphatases (missing for two participants), -albumin or -protein concentration (missing for eight participants), -total calcium or -calcium ionised (missing for three participants), and serum-phosphate (missing for three participants).

Statistical comparison between subject groups was carried out with the MannWhitney rank sum test for unpaired data.

\section{Results}

The blood tests showed, apart from two participants with recent infections corresponding to subnormal haemoglobin concentrations and high ERS, values which largely were within the normal range for the tests. In particular all serum-creatinine, alkaline phosphatase, calcium, and phosphate values were normal, apart from one subnormal phosphate value. 
Table III Bone mineral content (BMC) of participants in per cent of normal values

\begin{tabular}{|c|c|c|c|c|}
\hline \multirow{2}{*}{$\begin{array}{l}\text { Participant } \\
\text { no. }\end{array}$} & \multicolumn{4}{|c|}{$\mathrm{BMC}$ in per cent of normal } \\
\hline & Lumbar spine & Femoral neck & Femoral shaft & Proximal tibia \\
\hline 1 & $120 \cdot 1$ & $62 \cdot 6$ & $77 \cdot 8$ & $47 \cdot 6$ \\
\hline 2 & - & $79 \cdot 8$ & $76 \cdot 1$ & - \\
\hline 3 & $106 \cdot 1$ & $55 \cdot 2$ & $48 \cdot 1$ & $37 \cdot 5$ \\
\hline 4 & $95 \cdot 0$ & $52 \cdot 7$ & $63 \cdot 0$ & - \\
\hline 5 & $120 \cdot 4$ & $61 \cdot 5$ & $58 \cdot 6$ & - \\
\hline 6 & $111 \cdot 0$ & - & $65 \cdot 0$ & - \\
\hline 7 & $91 \cdot 0$ & $71 \cdot 7$ & $82 \cdot 5$ & - \\
\hline 8 & 1200 & 86.8 & $87 \cdot 1$ & $83 \cdot 6$ \\
\hline 9 & $127 \cdot 2$ & $90 \cdot 0$ & $72 \cdot 2$ & $43 \cdot 2$ \\
\hline 10 & $151 \cdot 2$ & - & $53 \cdot 5$ & $31 \cdot 7$ \\
\hline 11 & $103 \cdot 0$ & $85 \cdot 1$ & $89 \cdot 1$ & $59 \cdot 1$ \\
\hline 12 & $105 \cdot 9$ & $80 \cdot 1$ & $83 \cdot 0$ & $38 \cdot 2$ \\
\hline 13 & $123 \cdot 9$ & $78 \cdot 3$ & $86 \cdot 7$ & $54 \cdot 7$ \\
\hline 14 & $115 \cdot 2$ & $66 \cdot 8$ & $73 \cdot 8$ & $50 \cdot 4$ \\
\hline 15 & $90 \cdot 2$ & $66 \cdot 8$ & $82 \cdot 2$ & $54 \cdot 8$ \\
\hline 16 & $134 \cdot 3$ & $69 \cdot 2$ & $87 \cdot 8$ & $38 \cdot 9$ \\
\hline 17 & $90 \cdot 4$ & - & $31 \cdot 2$ & - \\
\hline 18 & $143 \cdot 3$ & $90 \cdot 7$ & $80 \cdot 7$ & $40 \cdot 3$ \\
\hline 19 & $106 \cdot 2$ & $58 \cdot 7$ & $70 \cdot 2$ & 38.9 \\
\hline 20 & $98 \cdot 0$ & $53 \cdot 1$ & $74 \cdot 8$ & $50 \cdot 4$ \\
\hline 21 & $98 \cdot 9$ & $96 \cdot 3$ & 83.0 & $40 \cdot 3$ \\
\hline 22 & $117 \cdot 0$ & $97 \cdot 0$ & $90 \cdot 7$ & $67 \cdot 7$ \\
\hline 23 & $56 \cdot 7$ & $47 \cdot 1$ & $35 \cdot 9$ & $20 \cdot 2$ \\
\hline 24 & $126 \cdot 8$ & $109 \cdot 7$ & $94 \cdot 2$ & $62 \cdot 0$ \\
\hline 25 & $93 \cdot 2$ & $72 \cdot 4$ & 82.5 & $62 \cdot 0$ \\
\hline 26 & $121 \cdot 8$ & $92 \cdot 0$ & $79 \cdot 9$ & $35 \cdot 2$ \\
\hline Average & $110 \cdot 7$ & $74 \cdot 9$ & $73 \cdot 4$ & $47 \cdot 8$ \\
\hline $\begin{array}{l}\text { Average with exclusion } \\
\text { of no. } 10,17 \& 23\end{array}$ & $112 \cdot 2$ & $76 \cdot 2$ & $77 \cdot 8$ & $50 \cdot 3$ \\
\hline
\end{tabular}

No. $10,17 \& 23$ were injured in childhood (5-10 years of age).

Table IV Bone mineral content (BMC) in per cent of normal values for participants with complete spinal cord motor lesions at the cervical (no. 1-6) and the thoracic (no. 9, 11-14, 1821) level. Minimum age at lesion was 15 years, and the measurements were carried out 6-23 years post-lesion

\begin{tabular}{lccccr}
\hline BMC & $\mathrm{n}$ & $\begin{array}{c}\text { Cervical lesion } \\
\text { median (range) }\end{array}$ & $\mathrm{n}$ & $\begin{array}{c}\text { Thoracic lesion } \\
\text { median (range) }\end{array}$ & P value \\
\hline Lumbar spine & 5 & $111 \cdot 0(95 \cdot 0-120 \cdot 4)$ & 9 & $106 \cdot 2(98 \cdot 0-143 \cdot 3)$ & \\
Femoral neck & 5 & $61 \cdot 5(52 \cdot 7-79 \cdot 8)$ & 9 & $80 \cdot 1(53 \cdot 1-96 \cdot 3)$ & $0 \cdot 10$ \\
Femoral shaft & 6 & $64 \cdot 0(48 \cdot 1-77 \cdot 8)$ & 9 & $80 \cdot 7(70 \cdot 2-89 \cdot 1)$ & $<0 \cdot 05$ \\
Proximal tibia & 2 & $(37 \cdot 5-47 \cdot 6)$ & 9 & $43 \cdot 2(38 \cdot 2-59 \cdot 1)$ & \\
\hline
\end{tabular}

P-value for statistical significance of differences between the BMC values for cervical and thoracic lesions was calculated by Mann-Whitney rank sum test for unpaired data.

Table III gives for all participants the BMC values in per cent of normal values. On average the BMC values for the lumbar spine was $11^{\circ}{ }_{0}$ higher than the normal value, while for the femoral neck and shaft the values were $25^{\circ}$ o lower than the normal values, and for the proximal tibia more than $50^{\circ}{ }_{0}$ lower than the normal values. Exclusion of the three participants who were injured in childhood increase the average BMC values as illustrated in Table III.

In Table IV are shown the BMC in per cent of normal values for participants 
Table V Bone mineral content (BMC) in per cent of normal values for paticipants with thoracic and lumbar spinal cord lesions with or without spasticity. Minimum age at lesion was 16 years, and the measurements were carried out 2-25 years post-lesion

\begin{tabular}{lcccc}
\hline \multicolumn{1}{c}{ BMC } & \multicolumn{2}{c}{ With spasticity $(\mathrm{n}=6)$} & \multicolumn{2}{c}{ Without spasticity $(\mathbf{N}=10)$} \\
mean & median (range) & mean & median (range) \\
\hline Lumbar spine & $112 \cdot 1$ & $113 \cdot 1(90 \cdot 2-134 \cdot 3)$ & $115 \cdot 2$ & $116 \cdot 1(93 \cdot 2-143 \cdot 3)$ \\
Femoral neck & $68 \cdot 8$ & $68 \cdot 0(53 \cdot 1-86 \cdot 8)$ & $88 \cdot 0$ & $90 \cdot 4(66 \cdot 8-109 \cdot 7)$ \\
Femoral shaft & $81 \cdot 5$ & $84 \cdot 5(70 \cdot 2-87 \cdot 8)$ & $82 \cdot 9$ & $82 \cdot 8(72 \cdot 2-94 \cdot 2)$ \\
Proximal tibia & $53 \cdot 6$ & $52 \cdot 6(38 \cdot 9-83 \cdot 6)$ & $49 \cdot 9$ & $46 \cdot 8(35 \cdot 3-67 \cdot 7)$ \\
Years since lesion & $9 \cdot 8$ & $6(2-25)$ & $12 \cdot 3$ & $13(2-23)$ \\
\hline
\end{tabular}

Table VI Bone mineral content (BMC) in per cent of normal values for participant with thoracic and lumbar spinal cord lesions using or not using long leg braces for a minimum of one hour daily in average. Minimum age at lesion was 16 years, and the measurements were carried out 2 to 25 years post-lesion

\begin{tabular}{lrcrc}
\hline \multicolumn{1}{c}{ BMC } & \multicolumn{2}{c}{ Using long leg braces $(\mathrm{n}=5)$} & \multicolumn{2}{c}{ Not using long leg braces $(\mathrm{n}=11)^{\circ}$} \\
mean & median (range) & mean & median (range) \\
\hline Lumbar spine & $109 \cdot 9$ & $106 \cdot 2(93 \cdot 2-134 \cdot 3)$ & $115 \cdot 9$ & $120 \cdot 0(90 \cdot 2-143 \cdot 3)$ \\
Femoral neck & $78 \cdot 7$ & $72 \cdot 4(58 \cdot 7-97 \cdot 0)$ & $81 \cdot 8$ & $85 \cdot 1(53 \cdot 1-109 \cdot 7)$ \\
Femoral shaft & $82 \cdot 8$ & $83 \cdot 0(70 \cdot 2-90 \cdot 7)$ & $82 \cdot 2$ & $83 \cdot 0(72 \cdot 2-94 \cdot 2)$ \\
Proximal tibia & $49 \cdot 6$ & $40 \cdot 3(38 \cdot 9-67 \cdot 7)$ & $52 \cdot 0$ & $50 \cdot 4(35 \cdot 3-83 \cdot 6)$ \\
Years since lesion & $9 \cdot 8$ & $8(2-21)$ & $12 \cdot 1$ & $10(2-25)$ \\
\hline
\end{tabular}

Table VII Bone mineral content (BMC) in per cent of normal values for participants with or without lower extremity fractures. The measurements were carried out minimum 10 years postlesion

\begin{tabular}{lcccccc}
\hline \multicolumn{1}{c}{ BMC } & \multicolumn{2}{c}{ With fractures } & \multicolumn{2}{c}{ Without fractures } \\
\multicolumn{1}{c}{ BM } & mean & median $($ range) & n & mean & median (range) \\
\hline Femoral neck & 6 & $72 \cdot 8$ & $75 \cdot 8(47 \cdot 1-96 \cdot 3)$ & 9 & $69 \cdot 1$ & $66 \cdot 8(52 \cdot 7-90 \cdot 7)$ \\
Femoral shaft & 9 & $63 \cdot 2$ & $65 \cdot 0(31 \cdot 2-83 \cdot 0)$ & 9 & $73 \cdot 3$ & $74 \cdot 8(48 \cdot 1-86 \cdot 7)$ \\
Proximal tibia & 4 & $32 \cdot 6^{\star}$ & $35 \cdot 0(20 \cdot 2-40 \cdot 3)$ & 8 & $48 \cdot 3 \star$ & $49 \cdot 0(37 \cdot 5-62 \cdot 0)$ \\
Years since lesion & 9 & $16 \cdot 8$ & $17(10-23)$ & 9 & $17 \cdot 8$ & $18(10-25)$ \\
\hline
\end{tabular}

${ }^{\star} \mathrm{p}<0.05$ (Mann-Whitney rank sum test for unpaired data).

with complete spinal cord motor lesions at the cervical versus the thoraic level. BMC values in the femoral shaft were significant lower for those participants with cervical lesions.

Neither presence of spasticity (Table V), nor daily use of long leg braces (Table VI) seemed to influence the BMC significantly. As shown in Table VII participants with previous fractures in the long bones of the lower extremities had significant lower BMC values in the proximal tibia and a trend towards lower values in the femur compared to BMC of participants without fractures. It should be noted that 9 of the 15 lower extremity fractures occurred in the three paraplegics who sustained their injury at childhood, and among them were the lowest measured BMC values.

\section{Discussion}

From tibial bone biopsies, collected 2 years after spinal cord injury, Chantraine et al., (1986) found that the distribution of cortical and cancellous bone was 
approaching that of normal subjects; thus suggesting that the bone remodelling 2 years post injury had reached a new steady state. Based on this finding it could be assumed that the participants in the present study had reached a level of relative stable $\mathrm{BMC}$, and at least should have so five years after sustaining their spinal cord lesion.

The average BMC of the lumbar spine in the participants was found to be a little higher than that of normals. This can in part be explained by the high $\mathrm{BMC}$ values in those participants with rod-spondylodesis in the scanned area. According to previous hypothesis regarding osteoporosis in spinal cord injured (Chantraine, 1978-79) it should have been expected that all bone below the neurological level of lesion would decrease in BMC. But as is shown this did not apply to the lumbar spine, not even in those participants with cervical cord lesions. A reason for the maintained normal BMC in the lumbar spine after spinal cord lesions might be that the lumbar spine continues to be weight loaded, mainly while sitting in a wheelchair, when the primary period of immobilisation has come to an end.

Regarding the level of BMC in the lower extremities after sustaining a spinal cord lesion no data are available in the literature for comparison. The greatest loss of BMC in the present study was found in the proximal tibia, which is in accordance with findings in paraplegic rats (Verhas, 1980), where the greatest calcium loss was observed in the metaphyseal-epiphyseal regions on either side of the femoro-tibial joint.

We found lower BMC values in the femur of participants with cervical than in those with thoracic spinal cord lesions. The reason for this is unknown, but might be viewed in the light that Naftchi et al. (1980) found higher collagen breakdown in tetraplegic than in paraplegic subjects. It should be recognised, however, that the collagen destroyed belongs to the skin as well as to the bone (Claus-Walker and Halstead, 1982).

No significant influence on the BMC values was found neither in those with spasticity nor in those with the daily use of long leg braces. If one points out trends in Tables V and VI, they are towards lower BMC values in those participants with spasticity and the daily use of long leg braces for a minimum of 1 hour on average, and this tends to be shorter in these groups.

That spasticity did not protect against loss of BMC in the lower extremities in the spinal cord injured can be seen in relation to the findings of Ragnarsson and Sell (1981). They found that the incidence of lower extremity fractures seemed not to be different in those with spastic or flaccid paralysis. Likewise Abramson (1948) concluded that 'the nature of the paralysis was not a factor in bone disturbances'. On the other hand, Comarr et al. (1962) found, that lower extremity fractures occurred more often with lower than with upper motor neuron lesions.

According to previous studies (Abramson, 1948; Kaplan et al., 1978, 1981; Strachan et al., 1985) it might be expected that the use of long leg braces would have resulted in higher BMC values in the lower extremities, although Wyse and Pattee's (1954) results did not support the hypothesis that weightbearing will prevent osteoporosis after spinal cord injury. One reason for not observing any difference in the present study might be that use of long leg braces do not give rise to very much direct weight-bearing on the long bones because the weight to 
a great extent is transmitted to the braces through the femoral manchets. This should, however, still cause weight loading to the femoral necks, but no difference in the BMC was found here either. Another reason can be that the extent of weight bearing has not been sufficient long in the present study to show any beneficial effect on the level of BMC. This should in particular be considered in that Phillips et al. (1984) could demonstrate a significant increase in BMC in the tibia when stimulating the leg by vibration. Furthermore it is a possibility that the mechanisms for bone loss and retainment are different in the spine and in the lower extremities.

The BMC was lower in participants with fractures of the lower extremities. In the present study three of the participants with fractures had sustained their spinal cord injury in childhood when the bone mass was not fully developed and thus never reached a normal level (Nishiyama et al., 1986).

\section{References}

ABRAmSON AS 1948 Bone disturbances in injuries to the spinal cord and cauda equina (paraplegia). Fournal of Bone and foint Surgery 30-A: 982-987.

Bergmann P, Heilporn A, Schoutens A, Paternot J, Tricot A 1977-78 Longitudinal study of calcium and bone metabolism in paraplegic patients. Paraplegia 15:147-159.

BoHR H, ScHAadT O 1982 Influence of age on bone mineral content in the femoral neck measured by dual photon absorptiometry. In DEQUEKER J, JOHNSTON CC (eds.): Non-invasive bone measurements: Methodological problems. IRL Press, Oxford, pp. 197-200.

BoHR H, SchaAdT O 1985 Bone mineral content of the femoral neck and shaft: Relation between cortical and trabecular bone. Calcified Tissue International 37:340-344.

BoHR H, SCHAADT O 1987 Mineral content of tibia as assessed by dual photon absorbtiometry. Acta Orthopaedica Scandinavica 58:557-559.

Chantraine A 1978-79 Actual concept of osteoporosis in paraplegia. Paraplegia 16:51-58.

Chantraine A, Nusgens B, Lapiere CM 1986 Bone remodelling during the development of osteoporosis in paraplegia. Calcified Tissue International 38:323-327.

Claus-Walker J, Halstead LS 1982 Metabolic and endocrine changes in spinal cord injury: IV. Computed neurologic dysfunctions. Archives of Medicine and Physical Rehabilitation 63:632-638.

COMARr AE, Hutchinson RH, Bors E 1962 Extremity fractures of patients with spinal cord injuries. American fournal of Surgery 103:732-739.

GRIFFITHS HJ, D'ORSI CJ, ZIMMERMAN RE 1972 Use of ${ }^{125}$ I photon scanning in the evaluation of bone density in a group of patients with spinal cord injury. Investigative Radiology 7:107-111.

Kaplan PE, Gandhavadi B, Richards L, GoldsChMidT J 1978 Calcium balance in paraplegic patients: Influence of injury duration and ambulation. Archives of Medicine and Physical Rehabilitation 59:447-450.

Kaplan PE, Roden W, Gilbert E, Richards L, Goldschmidt JW 1981 Reduction or hypercalcuria in tetraplegia after weight-bearing and strengthening exercises. Paraplegia 19:289293.

Minaire P, Berard E, Meunier PJ, Edouard C, Goldert G, Pilonchery G 1981 Effects of disodium dichloromethylene diphosphonate on bone loss in paraplegic patients. fournal of Clinical Investigation 68:1086-1092.

Minaire P, Meunier P, Edouard C, Bernhard J, Courpon P, Bourret J 1974 Quantitative histological data on disuse osteoporosis. Comparison with biological data. Calcified Tissue Research 17:57-73.

Naftchi NE, Viau AT, Sell GH, Lowman EW 1980 Mineral metabolism in spinal cord injury. Archives of Medicine and Physical Rehabilitation 61:139-142.

Nishiyama S, Kuwahara T, Matsuda I 1986 Decreased bone density in severely handicapped children and adults, with reference to the influence of limited mobility and anticonvulsant medication. European fournal of Pediatrics 144:457-463.

NotTAGE WM 1981 A review of long-bone fractures in patients with spinal cord injuries. Clinical Orthopaedics 155:65-70.

Phillips CA, Petrofsky JS, Hendershot DM, Stafford D 1984 Functional electrical exercise. A comprehensive approach for physical conditioning of the spinal cord injured patient. Orthopaedics 7:1112-1123. 
RAGNARSSON KT, SELL GH 1981 Lower extremity fractures after spinal cord injury: A retrospective study. Archives of Medicine and Physical Rehabilitation 62:418-423.

SCHAADT O, BoHR H 1982 Bone mineral by dual photon absorptiometry. Accuracy-precision-sites of measurements. In Dequeker J, Johnston CC jr. (eds.): Non-invasive bone measurements. Methodological problems. IRL Press, Oxford, pp. 59-72.

STRACHAN RK, COOK J, WILKIE W, KENNEDY NSJ 1985 An evaluation of pneumatic orthoses in thoracic paraplegia. Paraplegia 23:295-305.

Verhas M, Martinella Y, Mone M, Heliporn A, Bergmann P, Tricot A, Schoutens A 1980 Demineralization and pathological physiology of the skeleton in paraplegic rats. Calcified Tissue International 30:83-90.

WySE DM, PATTEE CJ 1954 Effect of the oscillating bed and tilt table on calcium, phosphorus and nitrogen metabolism in paraplegia. American fournal of Medicine 17:645-661. 